\title{
Perioperative Care of a Child With Williams Syndrome
}

\author{
Karen M. Millera, e, Vidya Raman ${ }^{\text {, c }}$, Peter Winch ${ }^{\text {, c }}$, Joseph D. Tobias ${ }^{\text {b, c, d }}$
}

\begin{abstract}
The classical clinical and physical findings of Williams syndrome include characteristic dysmorphic features, congenital heart disease, and distinctive behavioral and emotional traits. In addition to acquired and congenital heart disease, manifestations in the renal, endocrine, musculoskeletal, and central nervous system may have implications during the perioperative period. Of primary concern during perioperative care is congenital and acquired heart disease as perioperative sudden death related to abnormalities of the coronary arteries has been reported. We present a 15-month-old child with Williams syndrome, who required anesthetic care for an emergent laparotomy due to an acute abdomen. The potential perioperative implications of Williams syndrome are discussed and previous published reports are reviewed.
\end{abstract}

Keywords: Williams syndrome; Perioperative care; Chromosome; $7 \mathrm{q} 11.23$

\section{Introduction}

Williams syndrome was initially described in 1961 by Williams et al [1]. It is now known that Williams syndrome is caused by a 1.5 megabase deletion on the long arm of chromosome 7 (7q11.23), which includes several genes, including the elastin gene $(\mathrm{ELN})[2,3]$. The reported incidence is approximately 1 in every 20,000 - 50,000 live births [4]. Typical clinical characteristics include developmental delay, characteristic elfin faces, distinctive emotional and behavioral traits, congenital heart disease, and idiopathic infantile hypercalcemia. In addition to the associated congenital heart disease, abnormalities of the coronary arteries have been described which may

Manuscript accepted for publication July 19, 2016

aThe Ohio State University College of Medicine, Columbus, OH, USA bDepartment of Anesthesiology \& Pain Medicine, Nationwide Children's Hospital, Columbus, OH, USA

'Department of Anesthesiology \& Pain Medicine, The Ohio State University College of Medicine, Columbus, OH, USA

${ }^{\mathrm{d} D e p a r t m e n t}$ of Pediatrics, The Ohio State University College of Medicine, Columbus, OH, USA

${ }^{\mathrm{e}}$ Corresponding Author: Karen Miller, The Ohio State University College of Medicine, Columbus, OH, USA. Email: Karen.Miller@osumc.edu

doi: http://dx.doi.org/10.14740/jmc2595w lead to coronary ischemia, arrhythmias, myocardial infarction, and sudden death. Congenital malformations may also involve ocular, auditory, dental, genitourinary, gastrointestinal, and musculoskeletal systems [5-7]. As a result of the multiorgan system involvement, anesthetic care may be necessary during various surgical or imaging procedures. We present a 15-month-old child with Williams syndrome who required anesthetic care during an emergency exploratory laparotomy for an acute abdomen. The potential perioperative implications of Williams syndrome are discussed and previous published reports are reviewed with a focus on the potential for sudden death.

\section{Case Report}

Institutional Review Board approval for publication is not required for single case report at Nationwide Children's Hospital (Columbus, OH). A 15 -month-old, $7.4 \mathrm{~kg}$ toddler presented to the emergency room from an outside hospital with fever, tachycardia, and abdominal tenderness with guarding. Her past medical history was significant for premature delivery at 32 weeks with intrauterine growth retardation followed by 3 weeks in the neonatal intensive care unit. A diagnosis of Williams syndrome was made at 10 months of age when the patient's mother began noting a regression in developmental milestones and she brought her daughter in for evaluation. The diagnosis was made based on characteristic facial features, supravalvar aortic stenosis, and peripheral pulmonary stenosis. The diagnosis was confirmed with a single nucleotide polymorphism (SNP) microarray. Associated conditions included developmental delay, hypotonia, hypokalemia, hypercalcemia, nephrocalcinosis, hypomagnesemia, severe bilateral peripheral pulmonary artery stenosis, and moderate supravalvar stenosis. The family history was incomplete, but available information was negative for other known birth defects, genetic diseases, intellectual disability, or learning disorders. Her last echocardiogram was performed in December 2015 which showed moderate bilateral peripheral pulmonary artery stenosis, mild supravalvar aortic stenosis, and a patent foramen ovale. Chamber sizes were noted to be normal along with right and left ventricular systolic function. No pericardial effusion was seen. Preoperative laboratory findings revealed normal blood urea nitrogen and creatinine. Hypokalemia was present with a potassium of $2.7 \mathrm{mmol} / \mathrm{L}$. The hemoglobin was $10.0 \mathrm{~g} / \mathrm{dL}$ and the hematocrit was $29.2 \%$. Based on the clinical and laboratory findings, it was decided that there was an intra- 
abdominal process causing an acute abdomen. Prior to transport to the operating room, an echocardiogram was performed which showed severe bilateral peripheral pulmonary artery stenosis, moderate supravalvar aortic stenosis with a mean gradient of $19 \mathrm{~mm} \mathrm{Hg}$, normal chamber sizes, normal right and left ventricular systolic function, and no pericardial effusion. Antibiotics to cover the intra-abdominal process (ciprofloxacin and metronidazole) were administered intravenously and the patient was transported to the operating room. Routine American Society of Anesthesiologists (ASA) monitors were placed. An intravenous rapid sequence induction was performed with the administration of midazolam (1 mg), fentanyl $(25 \mu \mathrm{g})$, and rocuronium $(10 \mathrm{mg})$. After loss of consciousness, cricoid pressure was applied and the trachea was intubated easily with a $4.0 \mathrm{~mm}$ cuffed tube. Following anesthetic induction and endotracheal intubation, a left radial arterial catheter and a second peripheral intravenous cannula were placed. Maintenance anesthesia included fentanyl and inhaled sevoflurane (expired concentration 2-4\%). Neuromuscular blockade for the procedure was provided by rocuronium. No intraoperative complications were noted. Surgery resulted in an excision of a performed Meckel's diverticulum. Total estimated blood loss was $15 \mathrm{~mL}$. Fluids administered included $150 \mathrm{~mL}$ of Lactated Ringers. After the procedure, the patient was transported to the pediatric intensive care unit (PICU) with her trachea intubated. She was sedated and ventilation controlled. Total anesthesia time was $2 \mathrm{~h} 32 \mathrm{~min}$. On postoperative day 0, the patient's trachea was extubated in the PICU without incident. The remainder of the postoperative course was unremarkable except for a slow return of gastrointestinal function and resumption of normal oral intake. The patient was discharged home on postoperative day 10 .

\section{Discussion}

In 1961, Williams et al reported four patients with supravalvar aortic stenosis, mental retardation, and a characteristic facies including broad forehead, wide-set eyes, drooping cheeks, and wide mouth [1]. Further studies on Williams syndrome have expanded the clinical findings to potentially include idiopathic infantile hypercalcemia, which can lead to gastrointestinal problems. Neurologic and behavioral characteristics may include attention deficit disorder, developmental delay, depression, and hyperacusis [7-11]. Due to the multisystem involvement of Williams syndrome, anesthetic care may be necessary for various radiologic or surgical procedures. Of primary concern during the perioperative care of these patients are previous reports of sudden cardiac death [4, 12-16]. Patients with congenital supravalvar aortic stenosis and associated peripheral pulmonary artery stenosis, the majority of whom have Williams syndrome, are at risk for development of myocardial ischemia resulting in sudden death due to arrhythmias or ventricular dysfunction [17, 18]. The biventricular hypertrophy resulting from the stenotic aortic and pulmonary lesions increases myocardial oxygen consumption and compromises oxygen delivery. There may also be direct compromise of coronary blood flow related to abnormalities of the coronary vasculature.

As with all anesthetic care, the first step is a careful preoperative assessment of the patient. In our case, although there was an emergent need to proceed to the operating room, there was ample time to obtain a focused preoperative history and physical exam, echocardiogram, and 12-lead electrocardiogram with a focused history to obtain clinical findings compatible with coronary ischemia. Even in the absence of such clinical history, patients with Williams syndrome should be considered to be at risk for coronary ischemia and sudden death. As such, perioperative control of factors that determine myocardial oxygen delivery and consumption is suggested. Myocardial delivery is determined by heart rate, left ventricular end-diastolic pressure (LVEDP), and diastolic blood pressure while myocardial oxygen demand is determined by heart rate, afterload, and LVEDP. Of primary importance is perioperative control of heart rate given its impact on both oxygen delivery and consumption.

During the perioperative care, a primary goal should be to maintain heart rate at an age-appropriate level. Vagolytic medications including atropine, glycopyrrolate, and pancuronium as well as sympathomimetic medications such as ketamine should be avoided or used with caution given their effects on heart rate [16]. Although frequently chosen for rapid sequence intubation in patients with compromised myocardial performance including congenital heart disease, the subsequent release of endogenous catecholamines following the administration of ketamine may lead to tachycardia as well as arrhythmias $[17,18]$. Although the use of etomidate has been discouraged given its effects on the endogenous production of corticosteroids, the risk-benefit ratio of its use versus propofol or other induction agents should be considered especially in patients with clinically significant stenotic lesions [19-21]. Likewise, maintenance anesthesia should focus on the use of agents that provide effective control heart rate with limited effects on diastolic blood pressure. While there is limited evidence-based to medicine to demonstrate a clinical difference, the limited positive chronotropic effects of sevoflurane may be preferable to isoflurane or desflurane. Furthermore, sevoflurane has less of a vasodilatory effect which may provide better maintenance of diastolic blood pressure and systemic vascular resistance. In addition to its negative chronotropic effects, dexmedetomidine has been shown to have beneficial effects on the balance between myocardial oxygen consumption and delivery in animal models [22]. Should tachycardia occur or there be clinical or electrocardiographic evidence of myocardial ischemia, heart rate control with esmolol should be considered [23]. In our patient, a combination of fentanyl and sevoflurane was chosen for anesthetic induction as well as maintenance anesthesia given their beneficial effects on heart rate and limited effects on diastolic blood pressure and systemic vascular resistance.

Craniofacial features can also impact the perioperative care of patients with Williams syndrome. A flattened midface, wide mouth, and poor dentition may lead to problems with mask ventilation and occasionally endotracheal intubation [6]. In our patient, there were no clinical features suggestive of problems with airway management and therefore a rapid sequence intubation was chosen to secure the airway given the presence of an intra-abdominal process. 
Table 1. Previous Reports of Anesthetic Care for Children With Williams Syndrome

\begin{tabular}{|c|c|c|}
\hline $\begin{array}{l}\text { Authors and } \\
\text { reference }\end{array}$ & Demographics and surgical procedure & Anesthetic care and outcomes \\
\hline $\begin{array}{l}\text { Horowitz } \\
\text { et al }[4]\end{array}$ & $\begin{array}{l}\text { Patient \#2: a 3-year-old girl for repair of } \\
\text { SVAS }\end{array}$ & $\begin{array}{l}\text { Patient with two cardiac arrests prior to cannulation for CPB. After repair of } \\
\text { SVAS, there was ongoing evidence of myocardial ischemia despite coronary artery } \\
\text { bypass grafting. LVAD was placed, but there was no recovery of postoperative } \\
\text { cardiac function. }\end{array}$ \\
\hline $\begin{array}{l}\text { Gupta et } \\
\text { al [12] }\end{array}$ & $\begin{array}{l}\text { A 5-year-old boy for preoperative CT } \\
\text { imaging prior to surgical repair of SVAS }\end{array}$ & $\begin{array}{l}\text { Anesthesia with sevoflurane in oxygen followed by succinylcholine. One minute } \\
\text { after Isovue }{ }^{\circledR} \text { contrast was administered, there was loss of pulses, ST depression, } \\
\text { and wide complex bradycardia. ACLS resuscitation included } 100 \% \text { oxygen } \\
\text { ventilation, chest compressions, atropine, epinephrine, bicarbonate, vasopressin, } \\
\text { and isoproterenol. No ROSC. }\end{array}$ \\
\hline $\begin{array}{l}\text { du Toit- } \\
\text { Prinsloo } \\
\text { et al }[13]\end{array}$ & $\begin{array}{l}\text { A 2-year-old boy presenting for } \\
\text { extraction of teeth under anesthesia }\end{array}$ & $\begin{array}{l}\text { Inhalation induction with sevoflurane. Tracheal intubation facilitated by alfentanil } \\
\text { and propofol. Immediately after endotracheal intubation, the patient developed } \\
\text { bradycardia and ST-segment elevation with cardiac arrest. CPR was started and } \\
\text { defibrillation attempts were made by external defibrillator. There was no ROSC. }\end{array}$ \\
\hline \multirow[t]{4}{*}{$\begin{array}{l}\text { Bird et } \\
\text { al }[15]\end{array}$} & $\begin{array}{l}\text { Patient \#1: a } 6 \text {-week-old boy presenting } \\
\text { for inguinal hernia repair }\end{array}$ & $\begin{array}{l}\text { During anesthetic induction, bradycardia and hypotension required CPR for } 1 \mathrm{~min} \text {. } \\
\text { He was resuscitated and surgery was completed. The patient died suddenly at } 6 \\
\text { years of age. }\end{array}$ \\
\hline & $\begin{array}{l}\text { Patient \#2: a 9-month-old girl presenting } \\
\text { for cardiac catheterization }\end{array}$ & $\begin{array}{l}\text { During the induction of anesthesia, bradycardia developed and proceeded to } \\
\text { cardiac arrest. No ROSC. }\end{array}$ \\
\hline & $\begin{array}{l}\text { Patient \#3: a 6-month-old girl presenting } \\
\text { for cardiac catheterization. }\end{array}$ & $\begin{array}{l}\text { Cardiac catheterization complicated by bradycardia and hypotension when } \\
\text { attempting to enter the pulmonary artery. CPR and operative relief of outflow tract } \\
\text { obstruction were unsuccessful. }\end{array}$ \\
\hline & $\begin{array}{l}\text { Patient \#7: a } 21 \text {-month-old boy } \\
\text { presenting for cardiac catheterization }\end{array}$ & $\begin{array}{l}\text { During balloon dilation of the left pulmonary artery, hypotension and bradycardia } \\
\text { occurred which progressed to full cardiac arrest. Resuscitation was unsuccessful. }\end{array}$ \\
\hline $\begin{array}{l}\text { Medley et } \\
\text { al [17] }\end{array}$ & $\begin{array}{l}\text { A } 7 \text {-month-old presenting for surgical } \\
\text { correction of subaortic and supravalvular } \\
\text { aortic stenosis }\end{array}$ & $\begin{array}{l}\text { Inhalation induction with sevoflurane and maintenance anesthesia of fentanyl. Cis- } \\
\text { atracurium for NM blockade. CPB anesthesia maintained by desflurane. Patient } \\
\text { was weaned from CPB with dopamine and epinephrine. Maintenance anesthesia } \\
\text { until end of procedure with desflurane in air/oxygen. No complications noted. }\end{array}$ \\
\hline $\begin{array}{l}\text { Bragg et } \\
\text { al [32] }\end{array}$ & $\begin{array}{l}\text { Patient \#1: a 3-year-old boy for } \\
\text { orchiopexy surgery. }\end{array}$ & $\begin{array}{l}\text { Serial cardiac arrests occurred during induction with ST wave changes, } \\
\text { bradycardia, hypotension, and pulseless electrical activity requiring full } \\
\text { resuscitation twice. The surgery was cancelled and a heart catheterization was } \\
\text { scheduled for the following day. The patient experienced several cardiac arrests } \\
\text { during the cardiac catheterization and was placed on ECMO and was transferred } \\
\text { for emergent cardiac surgery. }\end{array}$ \\
\hline $\begin{array}{l}\text { Monfared } \\
\text { et al }[33]\end{array}$ & $\begin{array}{l}\text { An 18-month-old boy presenting for } \\
\text { adenotonsillectomy }\end{array}$ & $\begin{array}{l}\text { Adenotonsillectomy was successfully performed. The patient was extubated } \\
\text { and being transferred from the operating room table, he became cyanotic and } \\
\text { bradycardic. CPR was initiated with atropine, epinephrine, volume boluses, and } \\
\text { electric defibrillation. Resuscitation was not successful. }\end{array}$ \\
\hline
\end{tabular}


Table 1. Previous Reports of Anesthetic Care for Children With Williams Syndrome - (continued)

\begin{tabular}{lll}
$\begin{array}{l}\text { Authors and } \\
\text { reference }\end{array}$ & Demographics and surgical procedure & Anesthetic care and outcomes \\
\hline Janna [34] & $\begin{array}{l}\text { An 8-year-old boy presenting for } \\
\text { emergent laparotomy }\end{array}$ & $\begin{array}{l}\text { Patient was premedicated with intranasal dexmedetomidine followed by anesthetic } \\
\text { induction with IV thiopentone, fentanyl, and atracurium. Anesthesia maintained } \\
\text { with sevoflurane. Intraoperative tachycardia managed with esmolol. Patient was } \\
\text { admitted to the PICU postoperatively and was discharged with no complications. }\end{array}$ \\
$\begin{array}{ll}\text { Asegaonkar } \\
\text { et al [35] }\end{array}$ & $\begin{array}{l}\text { A 3.5-year-old female presenting for } \\
\text { cleft palate repair }\end{array}$ & $\begin{array}{l}\text { Topical local anesthetic cream, antibiotic, and injection of tranexamic acid prior to } \\
\text { induction. Anesthetic induction with fentanyl, midazolam, propofol, ketamine, and } \\
\text { atracurium. Maintenance anesthesia with nitrous oxide, isoflurane, and atracurium. } \\
\text { One episode of tachycardia was treated with fentanyl and deepening of anesthesia } \\
\text { with isoflurane. No perioperative complications. }\end{array}$ \\
$\begin{array}{l}\text { Sahin et } \\
\text { al [36] }\end{array}$ & $\begin{array}{l}\text { A 5-month-old male infant presenting } \\
\text { for inguinal hernia repair }\end{array}$ & $\begin{array}{l}\text { Anesthetic induction with sevoflurane and nitrous oxide. } \\
\text { Maintenance anesthesia with sevoflurane in a nitrous oxide } \\
\text { and IV fentanyl. No postoperative complications. }\end{array}$ \\
$\begin{array}{l}\text { Boncagni } \\
\text { et al [37] }\end{array}$ & $\begin{array}{l}\text { A 12-year-old girl presenting for } \\
\text { correction thoracic kyphoscoliosis }\end{array}$ & $\begin{array}{l}\text { Anesthetic induction with fentanyl and propofol. Maintenance anesthesia with } \\
\text { sevoflurane and remifentanil. Correction of original kyphoscoliosis was impossible } \\
\text { due to excessive rigidity of the spine. No other complications noted. }\end{array}$ \\
$\begin{array}{l}\text { Kawahito } \\
\text { et al [38] }\end{array}$ & $\begin{array}{l}\text { A 15-year-old girl presenting for } \\
\text { aortoplasty for SVAS }\end{array}$ & $\begin{array}{l}\text { Premedication with atropine and midazolam. Anesthesia induced with fentanyl and } \\
\text { thiamyal. Maintenance anesthesia with nitrous oxide, oxygen, sevoflurane, and } \\
\text { fentanyl. Neuromuscular blockade with vecuronium. Weaned from CPB with } \\
\text { dopamine and prostaglandin E1. Postoperative course was uneventful. }\end{array}$ \\
\hline
\end{tabular}

IM: intramuscular; ROSC: return of spontaneous circulation; SVAS: supravalvular aortic stenosis; LVAD: left-ventricular assist device; CPB: cardiopulmonary bypass; CPR: cardiopulmonary resuscitation; ECMO: extracorporeal membrane oxygenation; PICU: pediatric intensive care unit; NM: neuromuscular.

The musculoskeletal system can also be affected in Williams syndrome patients. Joint laxity can result in contractures and variable degrees of hypotonia and muscle weakness have been reported. Variability in muscle fiber size and quantity of lipids stored can interfere with the effects of neuromuscular blockades with the potential of increasing the effects of these agents $[17,24,25]$. The potential for hypotonia may affect perioperative care, impacting decisions regarding the use of neuromuscular blocking agents (NMBAs), especially with regard to the safety of using succinylcholine and the potential for hyperkalemia [26]. Given the need for rapid sequence intubation and the anticipated duration of the procedure and clinical circumstances, rocuronium was chosen for our patient. In specific circumstances, rapid sequence intubation can be performed without NMBAs using a combination of propofol and remifentanil [27]. No prolongation of effect was noted; however, endotracheal intubation and mechanical ventilation were continued into the postoperative period and therefore no attempt was made to reverse neuromuscular blockade at the completion of the procedure with neostigmine. Alternatively, where available, sugammadex may provide an additional margin of safety for reversal of the neuromuscular blocking effects of rocuronium or vecuronium [28]. Several of previous reports of anesthetic care for patients with Williams syndrome have demonstrated the successful use of atracurium for the provision of short-term neuromuscular blockade [29-31].

Central nervous system (CNS) pathology and involvement with Williams syndrome is quite variable. Developmental delay, visuospatial deficits, and seizures have been reported. Endocrine and gastrointestinal involvements include gastrointestinal reflux which can be worsened in the presence of hypercalcemia. Side effects of these endocrine and gastrointestinal issues include abdominal pain, poor feeding, emesis, constipation, failure to thrive, and irritability that can progress to hypercalciuria, nephrocalcinosis, and abnormal electrocardiograms. Hypothyroidism occurs in approximately $10 \%$ of Williams patients [18]. Renal involvement is frequently seen presenting as elevated plasma creatinine and blood urea nitrogen, hypercalcemia-induced nephrocalcinosis, and renovascular hypertension. Reported structural abnormalities include renal aplasia, horseshoe kidney and renal cysts. Preoperative laboratory evaluating of renal function and a urinalysis are suggested prior to anesthetic care.

Previous reports of anesthetic care for Williams syndrome are summarized in Table 1 [4, 12-15, 17, 32-38].

Reducing the risk of myocardial ischemia is key when planning the anesthetic technique for these patients. Burch et al provided the following suggestions for anesthesia goals including preservation of sinus rhythm, avoidance of anesthetic drugs that may cause or worsen ischemia as well as maintaining systemic vascular resistance, preload, and contractility [16]. Anesthetic agents should be chosen to optimize the balance between oxygen delivery and consumption. The tenuous nature of these patients and importance of controlling these factors is exemplified by reports of sudden death during anesthetic care and procedural sedation. In many of the reported cases, the patients rapidly deteriorated from hypotension or bradycardia to asystole. Many did not respond despite aggressive and appropriate resuscitative measures. The timing of such problems has been noted before the procedure began, during the procedure, and after what appeared to be a successful completion. The preoperative evaluation should include an electrocardiograph and 
echocardiogram as well as consultation with pediatric cardiology as time permits. A pediatric anesthesiologist with training or experience in cardiac anesthesia is suggested. Care should be provided in an institution where postoperative PICU care is feasible. Patients should be closely monitored postoperatively to ensure homeostasis during surgical recovery. When treating high risk patients with severe cardiovascular disease, a site with extracorporeal membrane oxygenation (ECMO) capabilities should be used. Standard ASA monitoring should be performed on all patients and given the rapid onset and progression of hemodynamic changes, invasive arterial blood pressure monitoring is suggested for prolonged or major surgical interventions. There should be resuscitation medications readily available including epinephrine, phenylephrine, and esmolol.

\section{Funding}

The case report received no external funding.

\section{Conflicts of Interest}

The authors report no conflicts of interest.

\section{References}

1. Williams JC, Barratt-Boyes BG, Lowe JB. Supravalvular aortic stenosis. Circulation. 1961;24:1311-1318.

2. Urban Z, Peyrol S, Plauchu H, Zabot MT, Lebwohl M, Schilling K, Green M, et al. Elastin gene deletions in Williams syndrome patients result in altered deposition of elastic fibers in skin and a subclinical dermal phenotype. Pediatr Dermatol. 2000;17(1):12-20.

3. Rodriguez-Revenga L, Badenas C, Carrio A, Mila M. Elastin mutation screening in a group of patients affected by vascular abnormalities. Pediatr Cardiol. 2005;26(6):827-831.

4. Horowitz PE, Akhtar S, Wulff JA, Al Fadley F, Al Halees Z. Coronary artery disease and anesthesia-related death in children with Williams syndrome. J Cardiothorac Vasc Anesth. 2002;16(6):739-741.

5. Jones KL. Williams syndrome: an historical perspective of its evolution, natural history, and etiology. Am J Med Genet Suppl. 1990;6:89-96.

6. Morris CA, Demsey SA, Leonard CO, Dilts C, Blackburn BL. Natural history of Williams syndrome: physical characteristics. J Pediatr. 1988;113(2):318-326.

7. Lashkari A, Smith AK, Graham JM, Jr. Williams-Beuren syndrome: an update and review for the primary physician. Clin Pediatr (Phila). 1999;38(4):189-208.

8. Garcia RE, Friedman WF, Kaback MM, Rowe RD. Idiopathic Hypercalcemia and Supravalvular Aortic Stenosis. Documentation of a New Syndrome. N Engl J Med. 1964;271:117-120.

9. Jue KL, Noren GR, Anderson RC. The syndrome of idiopathic hypercalcemia of infancy with associated con- genital heart disease. J Pediatr. 1965;67:1130-1149.

10. Bonham-Carter Re, Sutcliffe J. A syndrome of multiple arterial stenosis in association with the severe form of idiopathic hypercalcemia. Arch Dis Child. 1964;39:418419.

11. Von Arnim G, Engel P. Mental retardation related to hypercalcemia. Dev Med Child Neurol. 1964;6:366-377.

12. Ross L, Shelley E. Mesonephric carcinoma of the ovary producing hypercalcemia. Am J Obstet Gynecol. 1968;100(3):418-421.

13. Meuten DJ, Capen CC, Kociba GJ, Cooper BJ. Hypercalcemia of malignancy: Hypercalcemia associated with an adenocarcinoma of the apocrine glands of the anal sac. Am J Pathol. 1982;108(3):366-370.

14. Gupta P, Tobias JD, Goyal S, Miller MD, Melendez E, Noviski N, De Moor MM, et al. Sudden cardiac death under anesthesia in pediatric patient with Williams syndrome: a case report and review of literature. Ann Card Anaesth. 2010;13(1):44-48.

15. du Toit-Prinsloo L, Dippenaar JM, Honey EM. Case report of sudden death in a child with Williams syndrome following administration of anaesthesia. South Afr J Anaesth Analg. 2005;21:23-26.

16. Upadhyay S, Seiden H, Epstein S. Left main coronary artery stenting after cardiac arrest in an infant with William's syndrome. Catheter Cardiovasc Interv. 2011;78(6):940944.

17. Bird LM, Billman GF, Lacro RV, Spicer RL, Jariwala LK, Hoyme HE, Zamora-Salinas R, Morris C, Viskochil D, Frikke MJ, Jones MC. Sudden death in Williams Syndrome: Report of 10 cases. J Pediatr. 1996;129:926-931.

18. Burch TM, McGowan FX, Jr., Kussman BD, Powell AJ, DiNardo JA. Congenital supravalvular aortic stenosis and sudden death associated with anesthesia: what's the mystery? Anesth Analg. 2008;107(6):1848-1854.

19. Medley J, Russo P, Tobias JD. Perioperative care of the patient with Williams syndrome. Paediatr Anaesth. 2005;15(3):243-247.

20. Matisoff AJ, Olivieri L, Schwartz JM, Deutsch N. Risk assessment and anesthetic management of patients with Williams syndrome: a comprehensive review. Paediatr Anaesth. 2015;25(12):1207-1215.

21. Scherzer D, Leder M, Tobias JD. Pro-con debate: etomidate or ketamine for rapid sequence intubation in pediatric patients. J Pediatr Pharmacol Ther. 2012;17(2):142149.

22. Tobias JD. Etomidate in pediatric anesthesiology: Where are we now? Saudi J Anaesth. 2015;9(4):451-456.

23. Komatsu R, You J, Mascha EJ, Sessler DI, Kasuya Y, Turan A. Anesthetic induction with etomidate, rather than propofol, is associated with increased 30-day mortality and cardiovascular morbidity after noncardiac surgery. Anesth Analg. 2013;117(6):1329-1337.

24. Tobias JD, Chrysostomou C. Dexmedetomidine: antiarrhythmic effects in the pediatric cardiac patient. Pediatr Cardiol. 2013;34(4):779-785.

25. Willigers HM, Prinzen FW, Roekaerts PM. The effects of esmolol and dexmedetomidine on myocardial oxygen consumption during sympathetic stimulation in dogs. $\mathrm{J}$ 
Cardiothorac Vasc Anesth. 2006;20(3):364-370.

26. Azar I. The response of patients with neuromuscular disorders to muscle relaxants: a review. Anesthesiology. 1984;61(2):173-187.

27. Ragoonanan V, Russell W. Anaesthesia for children with neuromuscular disease. Contin Educ Anaesth Crit Care Pain. 2010;10:143-147.

28. Martyn JA, Richtsfeld M. Succinylcholine-induced hyperkalemia in acquired pathologic states: etiologic factors and molecular mechanisms. Anesthesiology. 2006;104(1):158-169.

29. Dewhirst E, Tobias JD, Martin DP. Propofol and remifentanil for rapid sequence intubation in a pediatric patient at risk for aspiration with elevated intracranial pressure. Pediatr Emerg Care. 2013;29(11):1201-1203.

30. Pani N, Dongare PA, Mishra RK. Reversal agents in anaesthesia and critical care. Indian $\mathrm{J}$ Anaesth. 2015;59(10):664-669.

31. Peterson TA, Todd DB, Edwards JE. Supravalvular aortic stenosis. J Thorac Cardiovasc Surg. 1965;50(5):734-741.

32. Bruno E, Rossi N, Thuer O, Cordoba R, Alday LE. Cardiovascular findings, and clinical course, in patients with Williams syndrome. Cardiol Young. 2003;13(6):532-536.

33. Andrzejowski J, Mundy J. Anaesthesia for MRI angiography in a patient with Williams syndrome. Anaesthesia. 2000;55(1):97-98.

34. Bragg K, Fedel GM, DiProsperis A. Cardiac arrest under anesthesia in a pediatric patient with Williams syndrome: a case report. AANA J. 2005;73(4):287-293.
35. Monfared A, Messner A. Death following tonsillectomy in a child with Williams syndrome. Int J Pediatr Otorhinolaryngol. 2006;70(6):1133-1135.

36. Janna V. Anaesthetic management of Williams syndrome. Sri Lankan J Anesth. 2016;24:51-53.

37. Asegaonkar B, Kulkarni JJ, Totla RJ, Kulkarni P, Asegaonkar S, Totla S. Perioperative management of cleft palate repair in a patient with Williams syndrome: A case report. Open J Anesth. 2013;3:57-60.

38. Sahin S, Colak A, Gunday I. Anesthesia management of a patient with Williams Syndrome. Internet J Anesth. 2006;1:11-13.

39. Dec W, Shetye PR, Grayson BH, Brecht LE, Cutting CB, Warren SM. Incidence of oronasal fistula formation after nasoalveolar molding and primary cleft repair. J Craniofac Surg. 2013;24(1):57-61.

40. Erk G, Taspinar V, Donmez F, Ornek D. Neuroaxial anesthesia in a patient with progressive systemic sclerosis : case presentation and review of the literature on systemic sclerosis. BMC Anesthesiol. 2006;6:11.

41. Boncagni F, Pecora L, Durazzi V, Ventrella F. Anesthesiological Management of a Patient with Williams Syndrome Undergoing Spine Surgery. Case Rep Anesthesiol. 2016;2016:1371095.

42. Kawahito S, Kitahata H, Kimura H, Tanaka K, Sakai Y, Hirose Y, Oshita S. Anaesthetic management of a patient with Williams syndrome undergoing aortoplasty for supravalvular aortic stenosis. Can J Anaesth. 1998;45(12):1203-1206. 